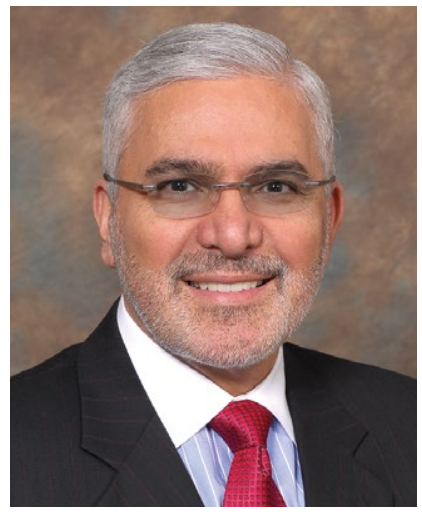

Henry A. Nasrallah, MD Editor-in-Chief

The pandemic has

permeated every

aspect of our complex

society and revealed

how fragile our'normal

lifestyle' really is
To comment on this

editorial or other topics

of interest:

henry.nasrallah

@currentpsychiatry.com

\title{
COVID-19 and the
}

\section{precipitous dismantlement of societal norms}

As the life-altering coronavirus disease 2019 (COVID-19) pandemic gradually ebbs, we are all its survivors. Now, we are experiencing COVID-19 fatigue, trying to emerge from its dense fog that pervaded every facet of our lives. We are fully cognizant that there will not be a return to the previous "normal." The pernicious virus had a transformative effect that did not spare any component of our society. Full recovery will not be easy.

As the uncertainty lingers about another devastating return of the pandemic later this year, we can see the reverberation of this invisible assault on human existence. Although a relatively small fraction of the population lost their lives, the rest of us are valiantly trying to readjust to the multiple ways our world has changed. Consider the following abrupt and sweeping burdens inflicted by the pandemic within a few short weeks:

Mental health. The acute stress of thanatophobia generated a triad of anxiety, depression, and nosophobia on a large scale. The demand for psychiatric care rapidly escalated. Suicide rate increased not only because of the stress of being locked down at home (alien to most people's lifestyle) but because of the coincidental timing of the pandemic during April and May, the peak time of year for suicide. Animal researchers use immobilization as a paradigm to stress a rat or mouse. Many humans immobilized during the pandemic have developed exquisite empathy towards those rodents! The impact on children may also have long-term effects because playing and socializing with friends is a vital part of their lives. Parents have noticed dysphoria and acting out among their children, and an intense compensatory preoccupation with video games and electronic communications with friends.

Physical health. Medical care focused heavily on COVID-19 victims, to the detriment of all other medical conditions. Non-COVID-19 hospital admissions plummeted, and all elective surgeries and procedures were put on hold, depriving many people of medical care they badly needed. Emergency department (ED) visits also declined dramatically, including the usual flow of heart attacks, stroke, pulmonary embolus, asthma attacks, etc. The minimization of driving greatly reduced the admission of accident victims to EDs. Colonoscopies, cardiac stents, hip replacements, MRIs, 
mammography, and other procedures that are vital to maintain health and quality of life were halted. Dentists shuttered their practices due to the high risk of infection from exposure to oral secretions and breathing. One can only imagine the suffering of having a toothache with no dental help available, and how that might lead to narcotic abuse.

Social health. The imperative of social distancing disrupted most ordinary human activities, such as dining out, sitting in an auditorium for Grand Rounds or a lecture, visiting friends at their homes, the cherished interactions between grandparents and grandchildren (the lack of which I painfully experienced), and even seeing each other's smiles behind the ubiquitous masks. And forget about hugging or kissing. The aversion to being near anyone who is coughing or sneezing led to an adaptive social paranoia and the social shunning of anyone who appeared to have an upper respiratory infection, even if it was unrelated to COVID-19.

Redemption for the pharmaceutical industry. The deadly pandemic intensified the public's awareness of the importance of developing treatments and vaccines for COVID-19. The often-demonized pharmaceutical companies, with their extensive $R \& D$ infrastructure, emerged as a major source of hope for discovering an effective treatment for the coronavirus infection, or-better still-one or more vaccines that will enable society to return to its normal functions. It was quite impressive how many pharmaceutical companies "came to the rescue" with clinical trials to repurpose existing medications or to develop new ones. It was very encouraging to see multiple vaccine candidates being developed and expedited for testing around the world. A process that usually takes years was reduced to a few months, thanks to the existing technical infrastructure and thousands of scientists who enable rapid drug development. It is possible that the public may gradually modify its perception of the pharmaceutical industry from a "corporate villain" to an "indispensable health industry" for urgent medical crises such as a pandemic, and also for hundreds of medical diseases that are still in need of safe, effective therapies.

Economic burden. The unimaginable nightmare scenario of a total shutdown of all businesses led to the unprecedented loss of millions of jobs and livelihoods, reflected in mileslong lines of families at food banks. Overnight, the government switched from worrying about its \$20-trillion deficit to printing several more trillion dollars to rescue the economy from collapse. The huge magnitude of a trillion can be appreciated if one is aware that it takes roughly 32 years to count to 1 billion, and 32,000 years to count to 1 trillion. Stimulating the economy while the gross domestic product threatens to sink by terrifying percentages $(20 \%$ to $30 \%)$ was urgently needed, even though it meant mortgaging the future, especially when interest rates, and servicing the debt, will inevitably rise from the current zero to much higher levels in the future. The collapse of the oncethriving airline industry (bookings were down an estimated 98\%) is an example of why desperate measures were needed to salvage an economy paralyzed by a viral pandemic.

Political repercussions. In our already hyperpartisan country, the COVID-19 crisis created more fissures across party lines. The blame game escalated as each side tried to exploit the crisis for political gain during a presidential election year. None of the leaders,
Editorial Staff

EDITOR Jeff Bauer

SENIOR EDITOR Sathya Achia Abraham ASSISTANT EDITOR Jason Orszt

WEB ASSISTANTS

Tyler Mundhenk, Kathryn Wighton

Art \& Production Staff

CREATIVE DIRECTOR Louise Koenig

ART DIRECTOR Pat Fopma

DIRECTOR, JOURNAL MANUFACTURING Michael Wendt

PRODUCTION MANAGER Donna Pituras

Publishing Staff

PUBLISHER Sharon Finch

DIRECTOR EBUSINESS DEVELOPMENT

Alison Paton

SENIOR DIRECTOR OF SALES

Tim LaPella

Editor-in-Chief Emeritus

James Randolph Hillard, MD

Frontline Medical Communications

VP, SALES Mike Guire

VP, DIGITAL CONTENT \& STRATEGY Amy Pfeiffer

PRESIDENT, CUSTOM SOLUTIONS JoAnn Wahl

VP, HUMAN RESOURCES \& FACILITY OPERATIONS Carolyn Caccavelli CIRCULATION DIRECTOR Jared Sonners DIRECTOR, CUSTOM PROGRAMS Patrick Finnegan

In affiliation with Global Academy for Medical Education, LLC

PRESIDENT David J. Small, MBA

\section{FRONTLLNE MLedge}

7 Century Drive, Suite 302

Parsippany, NJ 07054

Tel: (973) 206-3434

Fax: (973) 206-9378

www.frontlinemedcom.com

Subscription Inquiries: subscriptions@mdedge.com

Published through an educational partnership with 


\section{The resilience of many families was tested as the exercise of freedoms collided with the fear of getting infected}

from mayors to governors to the president, had any notion of how to wisely manage an unforeseen catastrophic pandemic. Thus, a political cacophony has developed, further exacerbating the public's anxiety and uncertainty, especially about how and when the pandemic will end.

Education disruption. Never before have all schools and colleges around the country abruptly closed and sent students of all ages to shelter at home. Massive havoc ensued, with a wholesale switch to solitary online learning, the loss of the unique school and college social experience in the classroom and on campus, and the loss of experiencing commencement to receive a diploma (an important milestone for every graduate). Even medical students were not allowed to complete their clinical rotations and were sent home to attend online classes. A complete paradigm shift emerged about entrance exams: the SAT and ACT were eliminated for college applicants, and the MCAT for medical school applicants. This was unthinkable before the pandemic descended upon us, but benchmarks suddenly evaporated to adjust to the new reality. Then there followed disastrous financial losses by institutions of higher learning as well as academic medical centers and teaching hospitals, all slashing their budgets, furloughing employees, cutting salaries, and eliminating programs. Even the "sacred" tenure of senior faculty became a casualty of the financial "exigency." Children's nutrition suffered, especially among those in lower socioeconomic groups for whom the main meal of the day was the school lunch, and was made worse by their parents' loss of income. For millions of people, the emotional toll was inevitable following the draconian measure of closing all educational institutions to contain the spread of the pandemic.

Family burden. Sheltering at home might have been fun for a few days, but after many weeks, it festered into a major stress, especially for those living in a small house, condominium, or apartment. The resilience of many families was tested as the exercise of freedoms collided with the fear of getting infected. Families were deprived of celebrating birthdays, weddings, funerals, graduation parties, retirement parties, Mother's Day, Father's Day, and various religious holidays, including Easter, Passover, and Eid al-Fitr.

Sexual burden. Intimacy and sexual contact between consenting adults living apart were sacrificed on the altar of the pernicious viral pandemic. Mandatory social distancing of 6 feet or more to avoid each other's droplets emanating from simple speech, not just sneezing or coughing, makes intimacy practically impossible. Thus, physical closeness became taboo, and avoiding another person's saliva or body secretions became a must to avoid contracting the virus. Being single was quite a lonely experience during this pandemic!

Entertainment deprivation. Americans are known to thrive on an extensive diet of spectator sports. Going to football, basketball, baseball, or hockey games to root for one's team is intrinsically American. The pursuit of happiness extends to attending concerts, movies, Broadway shows, theme parks, and cruises with thousands of others. The pandemic ripped all those pleasurable leisure activities from our daily lives, leaving a big hole in people's lives at the precise time fun activities were needed as a useful diversion from the dismal stress of a pandemic. To make things worse, it is uncertain 


\section{The switch to telepsychiatry was advantageous for both patients and psychiatrists because this technology is well-suited for psychiatric care}

continued from page 14

\section{Table}

\section{Lexicon of coronavirus terms}

\begin{tabular}{l|l}
\hline Community spread & Novel coronavirus \\
\hline Containment & Personal protective equipment (PPE) \\
\hline COVID-19 (coronavirus disease 2019) & Physical distancing \\
\hline Cytokine storm & Quarantine \\
\hline Drive-thru testing & Remdesivir \\
\hline Droplet transmission & Respirator \\
\hline Fatality rate & Severe acute respiratory syndrome (SARS) \\
\hline Flatten the curve & Shelter at home \\
\hline Fomite & Social distancing \\
\hline Hydroxychloroquine & Stay-at-home order \\
\hline Immunocompromised & Stimulus \\
\hline Incubation period & Superspreader \\
\hline Isolation & Trillions \\
\hline Middle East respiratory syndrome (MERS) & Underlying medical condition \\
\hline Mitigation & Ventilators \\
\hline mRNA-1273 vaccine & Warp-speed vaccines \\
\hline N95 mask &
\end{tabular}

when (if ever) such group activities will be restored, especially if the pandemic returns with another wave. But optimists would hurry to remind us that the "Roaring 20s" blossomed in the decade following the 1918 Spanish Flu pandemic.

Legal system. Astounding changes were instigated by the pandemic, such as the release of thousands of inmates, including felons, to avoid the spread of the virus in crowded prisons. For us psychiatrists, the silver lining in that unexpected action is that many of those released were patients with mental illness who were incarcerated because of the lack of hospitals that would take them. The police started issuing citations instead of arresting and jailing violators. Enforcement of the law was welcome when it targeted those who gouged the public for personal profit during the scarcity of masks, sanitizers, or even toilet paper and soap.
Medical practice. In addition to delaying medical care for patients, the freeze on so-called elective surgeries or procedures (many of which were actually necessary) was financially ruinous for physicians. Another regrettable consequence of the pandemic is a drop in pediatric vaccinations because parents were reluctant to take their children to the pediatrician. On a more positive note, the massive switch to telehealth was advantageous for both patients and psychiatrists because this technology is well-suited for psychiatric care. Fortunately, regulations that hampered telepsychiatry practice were substantially loosened or eliminated, and even the usually sacrosanct HIPAA regulations were temporarily sidelined.

Medical research. Both human and animal research came to a screeching halt, and many research assistants were furloughed. Data collection was disrupted, and a generation of scientific 
and medical discoveries became a casualty of the pandemic.

Medical literature. It was stunning to see how quickly COVID-19 occupied most of the pages of prominent journals. The scholarly articles were frankly quite useful, covering topics ranging from risk factors to early symptoms to treatment and pathophysiology across multiple organs. As with other paradigm shifts, there was an accelerated publication push, sometimes with expedited peer reviews to inform health care workers and the public while the pandemic was still raging. However, a couple of very prominent journals had to retract flawed articles that were hastily published without the usual due diligence and rigorous peer review. The pandemic clearly disrupted the science publishing process.

Travel effects. The steep reduction of flights (by 98\%) was financially catastrophic, not only for airline companies but to business travel across the country. However, fewer cars on the road resulted in fewer accidents and deaths, and also reduced pollution. Paradoxically, to prevent crowding in subways, trains, and buses, officials reversed their traditional instructions and advised the public to drive their own cars instead of using public transportation!

Heroism of front-line medical personnel. Everyone saluted and prayed for the health care professionals working at the bedside of highly infectious patients who needed 24/7 intensive care. Many have died while carrying out the noble but hazardous medical duties. Those heroes deserve our lasting respect and admiration.

The COVID-19 pandemic insidiously permeated and altered every aspect of our complex society and revealed how fragile our "normal lifestyle" really is. It is possible that nothing will ever be the same again, and an uneasy sense of vulnerability will engulf us as we cautiously return to a "new normal." Even our language has expanded with the lexicon of pandemic terminology (Table, page 16). We all pray and hope that this plague never returns. And let's hope one or more vaccines are developed soon so we can manage future recurrences like the annual flu season. In the meantime, keep your masks and sanitizers close by...

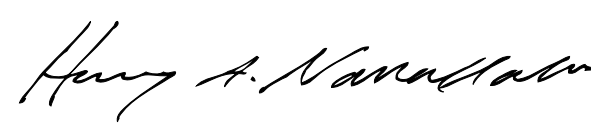

Henry A. Nasrallah, MD

Editor-in-Chief

Postscript: Shortly after I completed this editorial, the ongoing COVID-19 plague was overshadowed by the scourge of racism, with massive protests, at times laced by violence, triggered by the death of a black man in custody of the police, under condemnable circumstances. The COVID-19 pandemic and the necessary social distancing it requires were temporarily ignored during the ensuing protests. The combined effect of those overlapping scourges are jarring to the country's psyche, complicating and perhaps sabotaging the social recovery from the pandemic.
It is possible that nothing will ever be the same again, and an uneasy sense of vulnerability will engulf us as we cautiously return to a 'new normal' 